\title{
CIENCIAMATRIA
}

Revista Interdisciplinaria de Humanidades, Educación, Ciencia y Tecnología

Año VII. Vol. VII. N¹2. Enero - Junio. 2021

Hecho el depósito de ley: pp201602FA4721

ISSN-L: 2542-3029; ISSN: 2610-802X

Universidad Nacional Experimental Francisco de Miranda (UNEFM). Santa Ana de Coro. Venezuela

Karla Paola Campoverde-Molina; Katina Vanessa Bermeo-Pazmiño

Diego Patricio Cisneros-Quintanilla

https://doi.org/10.35381/cm.v7i12.441

\section{La gerencia administrativa en la Universidad Católica de Cuenca mediante teletrabajo durante el confinamiento}

\section{Administrative management at the Catholic University of Cuenca through teleworking during confinement}

\author{
Karla Paola Campoverde-Molina \\ kcampoverde@ucacue.edu.ec \\ Universidad Católica de Cuenca, Cuenca \\ Ecuador \\ https://orcid.org/0000-0002-7681-3193 \\ Katina Vanessa Bermeo-Pazmiño \\ kbermeo@ucacue.edu.ec \\ Universidad Católica de Cuenca, Cuenca \\ Ecuador \\ https://orcid.org/0000-0002-4438-7855 \\ Diego Patricio Cisneros-Quintanilla \\ dcisneros@ucacue.edu.ec \\ Universidad Católica de Cuenca, Cuenca \\ Ecuador \\ https://orcid.org/0000-0003-0897-8938
}

Recibido: 01 de octubre de 2020

Aprobado: 15 de diciembre de 2020 


\title{
RESUMEN
}

El teletrabajo es una modalidad de trabajo cada vez más común a nivel mundial ya que permite a las empresas aumentar su productividad y reducir costos y tiempos. Al presentarse la emergencia sanitaria por el COVID 19, la Universidad Católica de Cuenca tuvo que cambiar la gestión administrativa de sus procesos para desarrollarlos en el marco del Teletrabajo. El objetivo de la investigación es determinar si la gestión administrativa en esta nueva modalidad funciona en su totalidad, analizando los procesos de las secretarías de las Unidades Académicas. Metodológicamente fue de tipo descriptivo transversal. Se evidenció un correcto funcionamiento en los procesos desarrollados, sin embargo, se propuso un plan de digitalización de los archivos físicos que permitirán tener un control y disminución en el tiempo de tramitación documental.

Descriptores: Educación; gestión; capital humano; percepción. (Palabras tomadas del Tesauro UNESCO).

\begin{abstract}
Teleworking is an increasingly common work modality worldwide as it allows companies to increase their productivity and reduce costs and time. When the health emergency due to COVID 19 arose, the Catholic University of Cuenca had to change the administrative management of its processes to develop them within the framework of Telework. The objective of the research is to determine if the administrative management in this new modality works in its entirety, analyzing the processes of the secretariats of the Academic Units. Methodologically, it was descriptive cross-sectional. Proper functioning was evidenced in the processes developed, however, a digitalization plan for the physical files was proposed that will allow control and decrease in the time of document processing.
\end{abstract}

Descriptors: Education; management; human resources; perception. (Words taken from the UNESCO Thesaurus). 


\section{INTRODUCCIÓN}

El teletrabajo es una modalidad de trabajo cada vez más común a nivel mundial en países desarrollados, este concepto nace por primera vez en Estados Unidos en la crisis petrolera que surgió a mediados de los 70, (Nilles, 1976) afirma que Estados Unidos no tendría la necesidad de importar petróleo si un trabajador urbano de cada siete no tuviera la necesidad de trasladarse a sus lugares de trabajo.

Por otro lado, (Brooking, 1997) manifiesta que, en el teletrabajo, gran parte de los empleados ya no tienen ni siquiera un lugar de trabajo, sino trabajan desde sus hogares, manteniendo la comunicación a través de las canales de la información con sus jefes y compañeros, esto le permite a la empresa reducir sus costos, así como un ahorro de tiempo. Así mismo (Pantoja-Aguilar \& Garza-Treviño, 2019), plantea que la gestión administrativa tiene un enfoque sistémico, ya que está encaminada al logro de objetivos mediante el proceso administrativo, es decir a través de la planeación, organización, dirección y control.

En el Ecuador, las Instituciones de Educación Superior, ofertan carreras en la modalidad presencial, semipresencial, dual en línea y a distancia, sin embargo, en lo que respecta a la gestión administrativa para el desarrollo de las actividades que genera este proceso educativo, se lo lleva a cabo de manera presencial exclusivamente. Los procesos administrativos estaban ya establecidos, utilizando los recursos físicos y herramientas tecnológicas propias de la institución para que los empleados cumplan así las responsabilidades asignadas dentro de su horario laboral.

Al presentarse la emergencia sanitaria por el COVID 19, las IES en la ciudad de Cuenca, se enfrentaron a grandes cambios y retos al buscar los recursos y herramientas que les permitan enfrentar dicha situación y continuar con sus procesos puesto que, al ser desarrollados presencialmente, no se tenía establecido otro proceso diferente al ya conocido, provocando en un corto tiempo la paralización parcial de sus actividades en el mejor de los casos y en otros la paralización total. 


\section{CIENCIAMATRIA \\ Revista Interdisciplinaria de Humanidades, Educación, Ciencia y Tecnología \\ Año VII. Vol. VII. N¹2. Enero - Junio. 2021 \\ Hecho el depósito de ley: pp201602FA4721 \\ ISSN-L: 2542-3029; ISSN: 2610-802X \\ Universidad Nacional Experimental Francisco de Miranda (UNEFM). Santa Ana de Coro. Venezuela \\ Karla Paola Campoverde-Molina; Katina Vanessa Bermeo-Pazmiño \\ Diego Patricio Cisneros-Quintanilla}

Debido a la situación que se enfrentaba, la administración en las IES debía cambiar para adaptarse a la nueva realidad que se está viviendo, buscando alternativas que les permitan retomar y desarrollar sus actividades diarias de la mejor forma posible, sin exponer al personal, viendo así en la implementación del Teletrabajo, un factor de innovación que les permita cumplir con las actividades propias de cada ámbito, pero al ser esta una nueva metodología para trabajar, se desconocía como poder implementarla, como iniciar la gestión del mismo, como capacitar al personal, como determinar si contaban con los equipos tecnológicos necesarios para poder trabajar desde casa, ya que sería un cambio de 180 grados en lo que respecta a procesos, trámites, documentación así como el tiempo invertido en los mismos, y por consiguiente un cambio radical en la gerencia de las IES.

La Universidad Católica de Cuenca, fue una de las IES afectadas por la pandemia del COVID 19, ya que los procesos administrativos se encontraban ya establecidos desarrollándose de manera presencial específicamente, por lo cual al darse la emergencia sanitara, ocasionó una paralización significativa en sus actividades, ya que no se tenía establecido un proceso diferente al ya conocido previamente, el personal administrativo no podía gestionar los procesos a su cargo, ya que los mismos en gran parte se desarrollaban con documentación física que reposa en los archivos de los distintos departamentos, bajo este panorama la Universidad tuvo que tomar medidas urgentes que le permitan adaptarse a esta nueva realidad y continuar con la gestión de todos los procesos en los que sea posible.

Una de las medidas adoptadas para poder enfrentar este problema fue la contratación de la plataforma ZOOM para lograr establecer la comunicación entre el personal de cada departamento, sin embargo al no contar con un modelo de aplicación de procesos administrativos para desarrollarlos en el marco del teletrabajo, cada departamento estableció e implemento de acuerdo a sus necesidades la metodología y desarrollo de sus procesos bajo esta modalidad, tratando de mantener la uniformidad de los mismos 


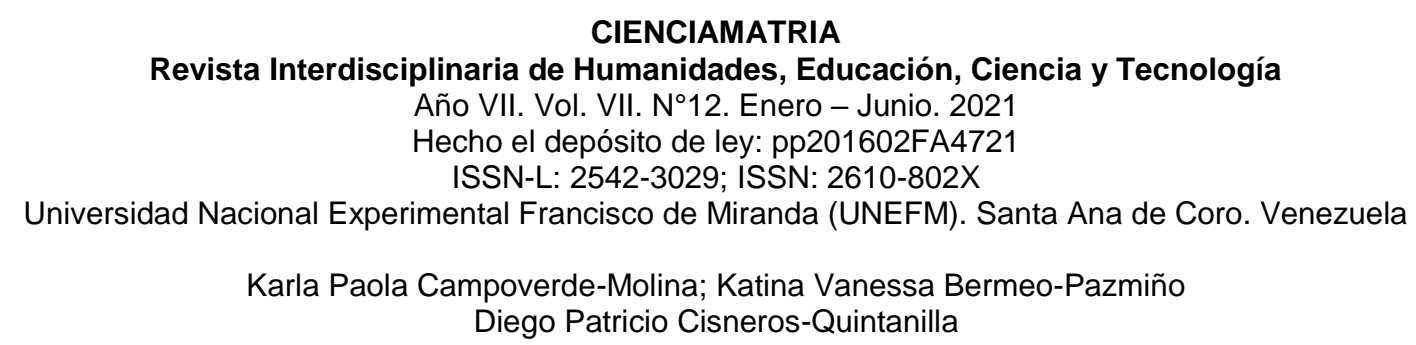

en gran parte, uno de los departamentos afectados que realizó este proceso fueron las secretarías de las Unidades Académicas, radicándose el problema en el desconocimiento de que si trabajar bajo esta modalidad realmente funcionaria.

El objetivo de la investigación es determinar si la gestión administrativa en esta nueva modalidad de trabajo implementada durante la emergencia sanitaria funciona en su totalidad para que el personal administrativo cumpla con las actividades y procesos asignados a su cargo como si los desarrollara de manera presencial analizando los procesos administrativos desarrollados bajo esta modalidad.

\section{Referencial Teórico}

\section{La gestión administrativa como pieza clave en el funcionamiento de las organizaciones}

Dentro del proceso administrativo es importante, como en toda ciencia, conocer de qué se trata el proceso de gestión, para poder llevarla de una manera óptima. (Fayol, 1980) conocido como el padre del proceso administrativo, menciona que esta doctrina administrativa donde se encuentran los procesos de prevención, organización, dirección, coordinación y control, los cuales se deben seguir para una correcta gestión administrativa, tiene el fin de facilitar la gestión empresarial, cualquiera sea el campo en el que se desempeñe la empresa.

Así mismo, (Koontz \& Weihrich, 1998) por su parte, definen a la gestión administrativa como un proceso de medición y corrección del trabajo, con el fin de que se cumplan los objetivos propuestos por la organización, así como los procedimientos establecidos para alcanzarlos.

Como complemento, (Münch \& García, 2004) definen la gestión administrativa como el conjunto de fases continuas que interactúan y constituyen un proceso completo, mediante el cual se puede efectuar la gestión de una empresa. Así, se puede definir a la gestión administrativa como el proceso organizado con el cual una empresa guía su 


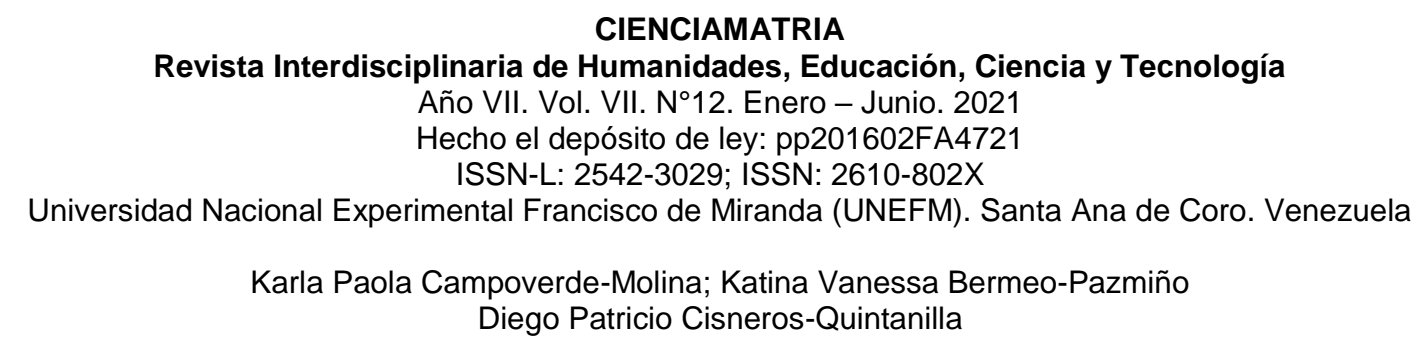

funcionamiento, facilitando la gestión administrativa, para poder tomar una correcta toma de decisiones y así alcanzar los objetivos de la empresa.

Como complemento de esta definición y para nuestro caso de estudio dentro de las Instituciones de Educación Superior, (Tünnermann-Bernheim, 2007) manifiesta que la gestión administrativa es una función de apoyo a la docencia e investigación en las instituciones de Educación Superior, no tiene sentido por sí misma, la función administrativa existe para que funcione bien la docencia, la investigación y los demás servicios académicos de la institución. Si la gestión es deficiente entorpece la labor académica y si la gestión es excelente se desarrollan de manera eficaz los programas y actividades académicas de la institución y, si, además, la gestión es estratégica, se fortalece la capacidad de la institución y sus miembros para responder de manera innovadora a las necesidades de su entorno.

Por otro lado, (Fayol, 1980) manifiesta que para que lograr una buena gestión en una organización, debe estar sujeta a un proceso administrativo que comprende cinco etapas: planificación, organización, dirección, coordinación y control. La planificación depende de la elaboración de un plan de acción, para que las operaciones de una empresa tengan éxito. La organización permite estructurar los recursos de una empresa tanto humanos como materiales para poder alcanzar los objetivos planteados.

La dirección permite guiar a la organización hacia un mismo objetivo mediante la motivación y estimulo en los intereses tanto personales como laborales. Por último, la coordinación facilita el trabajo y desarrollo de las actividades de una organización, para que todas las partes involucradas sean beneficiadas, además el control permite verificar que todas las actividades se hayan realizado conforme todo lo planificado en un inicio. Por su parte, (Louffat, 2015) señala que ha identificado cuatro etapas: planeación, organización, dirección y control.

La planeación es el primer elemento en tomar en cuenta en el proceso administrativo, ya que este elemento es responsable de establecer las bases de una excelente 


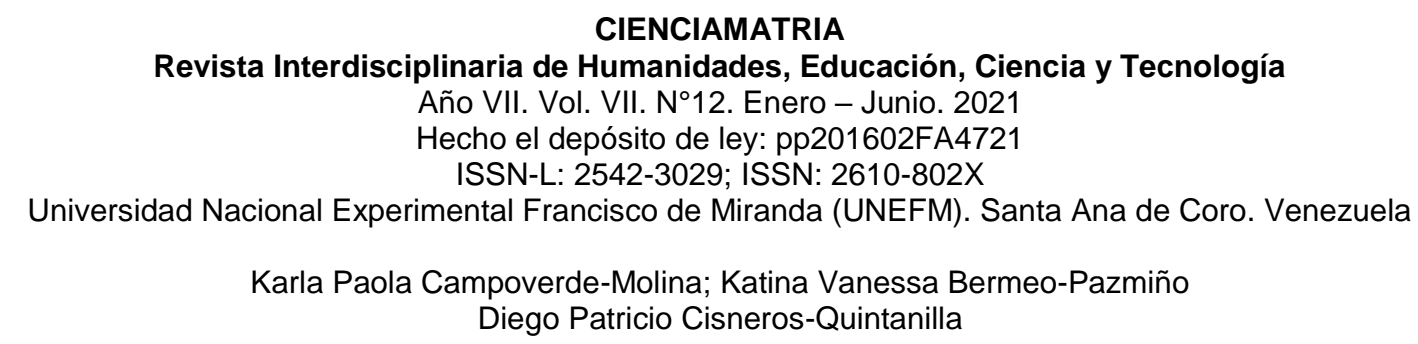

administración profesional en una organización, además es una guía sobre el rumbo que debe tomar la empresa, que decisiones debe tomar para alcanzar los objetivos planteados, para ser sostenible y rentable en el tiempo. Además, este elemento implica decisiones sobre escenarios futuros tanto de certidumbre como de incertidumbre. En cambio, la organización es responsable del ordenamiento interno de una empresa, pero guardando relación con la planificación estratégica ya planteada anteriormente.

Algunos autores van más allá y no hablan solamente de planificación, sino de planificación estratégica, en este aspecto, (García, 2013), menciona que este paso resalta la importancia de relación entre procesos. Así, la empresa debe crear estrategias que de una u otra forma impacten positivamente en todas las áreas de la empresa, teniendo en cuenta que detrás de la organización siempre hay personas.

En este sentido, (Duran, et al., 2017) añaden que las empresas deben estar preparadas para la identificación oportuna de la necesidad de transformación, así como la capacidad de esta para su adaptación. Así, los administradores deben implementar el uso de herramientas útiles para promover la eficiencia del talento humano, para que se comprometan con los objetivos de la institución y obtener ventajas duraderas en el paso del tiempo. Estas ideas derivan al hecho que en la planificación se deben definir las metas y estrategias de la empresa.

La dirección son las decisiones y acciones que implementan estrategias planificadas, así se conseguirá que la organización se adapte a su entorno de forma competitivamente superior para alcanzar las metas de la organización (Draf, 2006). En complemento, (Porter, 1980) menciona que la dirección de la empresa es el modelo de decisiones que se dan en una empresa y que revelan los objetivos, propósitos y metas, luego, (Ansoff, 1965) complementa al decir que la dirección en la empresa es la guía del curso de las acciones de una empresa para alcanzar sus objetivos. Por otro lado, (Cuervo, 1999) menciona que esta dirección se enfoca en la empresa en su interior y tiene incertidumbre en su entorno, competidores y otras complejidades. 


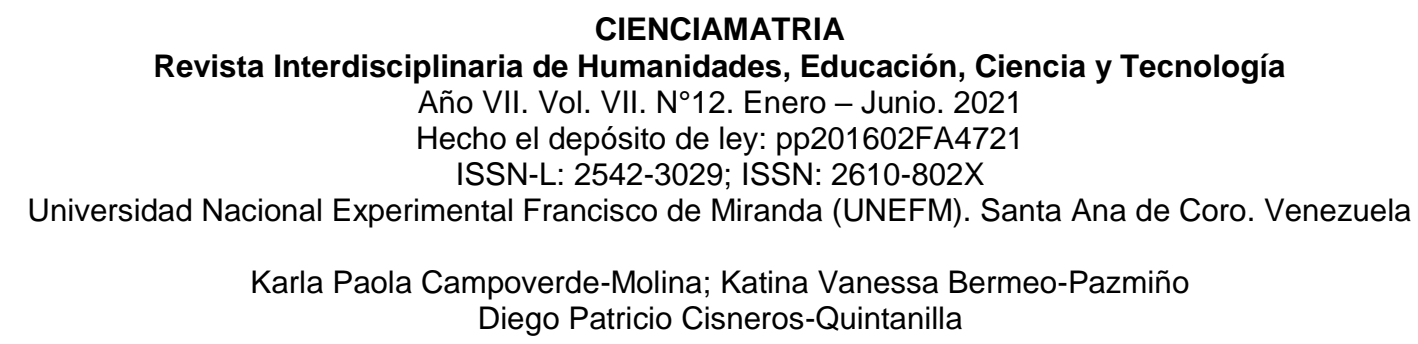

Así mismo, (Pérez-Carballo, 2008) indica que en el proceso de control se debe diferenciar el control de las actividades y el control de la gestión de responsables. El primero evalúa si un producto, proyecto o división es conveniente para la empresa y si es necesario mantenerlos. El control aborda el desempeño de los gestores ya que es muy común que una actividad atractiva esté mal gestionada o viceversa. El control de gestión se debe concentrar en los procesos más importantes.

La gestión administrativa es vital en las decisiones de una organización, (Robbins, 1987) menciona que la toma de decisiones en una empresa no difiere mucho de la toma de decisiones en un proceso de la vida común, entonces, se puede mencionar algo lógico, y es que para la toma de decisiones se debe escoger entre dos o más alternativas, y este proceso por lo tanto no va a ser diferente en una situación simple o compleja.

Como complemento de esta definición, (Moody, 1983) estableció de un modo este proceso de toma de decisiones como un circuito cerrado, que inicia tomando conciencia sobre un problema, reconociéndolo y definiéndolo. Luego se plantean y analizan alternativas y consecuencias, evaluándolas críticamente, junto con sus ventajas y desventajas, para finalmente seleccionar la solución entre alternativas escogidas y evaluadas.

\section{La importancia y objetivos de una correcta gestión documental}

En este sentido, (Russo, 2009) menciona que la gestión documental es el conjunto de actividades que permiten coordinar y controlar los aspectos relacionados con creación, recepción, organización almacenamiento, preservación, acceso y difusión de documentos, los cuales deben estar orientados a las personas que los utilizarán. Por su procedencia, la información en una empresa se puede categorizar como ambiental, interna y corporativa. 
La ambiental son todas las fuentes que se utilizan materialmente, forma el conjunto de documentación de la empresa, normalmente en la biblioteca, en donde se encuentra información externa. La interna es la documentación operativa como facturas o recibos. La corporativa es la información que la empresa comunica al exterior, como, folletos, presentación corporativa, catálogos, memorias públicas y demás. (Cruz-Mundet, 2006) plantea que la gestión documental tiene como objetivos:

1. Simplificar procesos

2. Disponibilidad de documentos esenciales

3. Organización correcta de los documentos para una gestión adecuada y toma oportuna de decisiones en la documentación.

Prosiguiendo, (Sánchez, 2014) manifiesta que la gestión documental ha evolucionado, no solo en la administración de documentos generados en papel, sino se han establecido parámetros para la elaboración de documentos electrónicos, todo esto como un factor que les permita aumentar la competitividad en las empresas y les permita solucionar problemas específicos en lo que respecta a una mejor toma de decisiones y un mejor servicio a sus usuarios. Una organización que no tiene una buena gestión en sus documentos posee las siguientes características:

1. Dificultad en la búsqueda de documentación

2. Una lenta toma de decisiones

3. Pérdida de documentación importante

\section{El Teletrabajo como herramienta fundamental en la evolución de las organizaciones}

Las Tecnologías de Información y Comunicación, se han convertido en una herramienta primordial en el desarrollo de las actividades diarias de las personas, así como de las organizaciones, (Havriluk \& Delgado, 2010), afirman que las TIC han generado un cambio en el estilo de vida de las personas así como su forma de relacionarse, así también han 


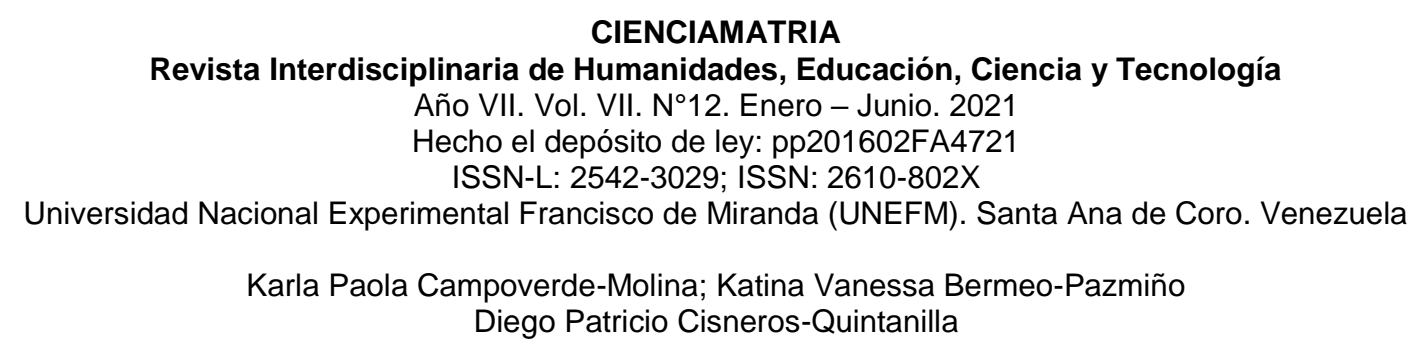

permitido potenciar los países, organizaciones y a las personas en lo que se refiere a una mejor calidad de vida, el impacto que tiene en el medio ambiente, en la salud y en diversos aspectos del diario vivir, lo que ha permitido el surgimiento de la herramienta del Teletrabajo. El teletrabajo abarca muchas definiciones, para comenzar tomamos como referencia su origen filosófico telou (griego) y tripaliare (latín), que significan lejos y trabajar, entendiéndolo como trabajo a distancia (Havriluk \& Delgado, 2010).

Por otro lado, (Buira, 2012) manifiesta que es una forma de trabajo que se ejecuta fuera de las oficinas de trabajo, utilizando equipos de cómputo y tecnologías de comunicación actuales, como instrumentos primordiales para el desarrollo de las actividades. (Escalante \& Ugas, 2005) manifiestan que el teletrabajo emplea la telemática en las organizaciones, considerando el tipo de contrato de trabajo que tiene con el trabajador, el lugar en el que va a cumplir y desarrollar las actividades asignadas a su cargo, sin la necesidad de un control externo por parte del empleador y con la utilización de recursos propios o proporcionados generalmente por la misma empresa.

Además sostienen que el teletrabajo persigue objetivos determinados dentro del ámbito socioeconómico, empresarial y con respecto a los trabajadores, los cuales les permiten el desarrollo del trabajo bajo esta modalidad. Dentro de los objetivos que se persiguen para la sociedad son:

1. Mejora en las condiciones del medio ambiente y disminución del congestionamiento del tráfico.

2. Facilidad a las personas con discapacidad para ingresar al ámbito laboral.

3. Mejora en la distribución de oportunidades laborales.

Dentro de los objetivos que se persiguen para las empresas se pueden señalar:

1. Agilidad, flexibilidad y aumento de la competitividad en las organizaciones.

2. Aumento en la capacidad de expansión, el cual les permite a las empresas cubrir mayormente la demanda del mercado.

3. Disminución de riesgos, así como los costos de mano de obra. 
Dentro de los objetivos que se persiguen para los trabajadores:

1. Aumento de la calidad de vida.

2. Mayor tiempo en familia

3. Libertad para la distribución del tiempo en la ejecución de tareas a su cargo.

En este sentido, (Belzunegui, 2001) señala que el teletrabajo debe cumpir tres condiciones:

1. El lugar de trabajo donde va a desarrollar sus actividades, debe ser fuera de la empresa, puede ser en su domicilio o en un sitio cercano al lugar de donde vive el trabajador.

2. Debe utilizar TICs, ya que el teletrabajo se desarrolla exclusivamente con estas herramientas y el trabajo manual no se considera para ser desarrollado bajo esta modalidad.

3. El desarrollo del trabajo a distancia se considera como un componente de vida fundamental para el trabajador no como algo ocasional.

En complemento, (Romero, 2006) manifiesta que para que un trabajador labore bajo esta modalidad debe reunir ciertas características, entre ellas la confidencialidad y la disposición a estar actualizado continuamente, así como también ofrece ventajas tanto para el empleado como a la empresa, entre las cuales se puede mencionar:

1. Establecer cuándo y en qué lugar desarrollar sus actividades.

2. Independencia en las decisiones de cómo desarrollar su trabajo y mayor productividad y eficiencia por parte de los trabajadores

3. Aumento en la calidad de vida y el tiempo de familia En consecución, (Martin, 2018) sostiene que las ventajas para el trabajador, al desarrollar sus actividades bajo esta modalidad le permite tener el control y flexibilidad en su horario de trabajo, ya que puede distribuir correctamente su tiempo para cumplir a cabalidad las tareas asignadas a su cargo, puede acceder a más oportunidades laborales ya que esta modalidad no le sujeta a un lugar o espacio físico determinado (Rodríguez, et al., 2019). 


\section{CIENCIAMATRIA \\ Revista Interdisciplinaria de Humanidades, Educación, Ciencia y Tecnología \\ Año VII. Vol. VII. N¹2. Enero - Junio. 2021 \\ Hecho el depósito de ley: pp201602FA4721 \\ ISSN-L: 2542-3029; ISSN: 2610-802X \\ Universidad Nacional Experimental Francisco de Miranda (UNEFM). Santa Ana de Coro. Venezuela \\ Karla Paola Campoverde-Molina; Katina Vanessa Bermeo-Pazmiño \\ Diego Patricio Cisneros-Quintanilla}

Para la organización, es una modalidad que le permite reducir costos, aumentar la productividad en su empresa, y por ultimo para la sociedad, el beneficio más grande es la reducción en los niveles de tráfico ocasionados por el desplazamiento diario que realizan las personas para llegar a sus lugares de trabajo, lo cual a su vez ayuda a disminuir favorablemente la contaminación en el medio ambiente, otro de los beneficios son mayores oportunidades de trabajo a las personas que tienen bajo su cuidado a familiares con capacidades especiales. Así como el teletrabajo, ofrece múltiples beneficios y ventajas, (Cano, et al., 2017) mencionan las desventajas para el trabajador que surgen con esta modalidad:

1. Aislamiento: el trabajador puede sentirse aislado, debido que al desarrollar sus actividades dentro de esta modalidad carece del poder interactuar con otras personas, de hacer vida social.

2. Desvalorización: el empleado puede sentir que no lo valoran, que no reconozcan su trabajo, así como estancado al realizar las mismas actividades sin tener la posibilidad de poder ascender.

3. Explotación laboral: puede darse una sobrecarga de trabajo ya que al tener un horario flexible el empleador puede aprovecharse de esta situación, sin respetar el horario de trabajo ni la cantidad de asignación de tareas al trabajador.

Para llevar a cabo el teletrabajo, existen diferentes espacios o lugares donde el trabajador puede realizar sus actividades, (Osio, 2010) ha identificado los siguientes espacios físicos:

1. Telecentros: se refiere a las instalaciones debidamente equipadas, para que el trabajador pueda ejecutar sus tareas, pero éstas no se encuentran necesariamente cerca de su domicilio.

2. Call centers: este está enfocado directamente a los espacios para los operadores telefónicos, los cuales pueden desarrollar sus actividades (recibir y realizar llamadas) utilizando centrales telefónicas. 
Universidad Nacional Experimental Francisco de Miranda (UNEFM). Santa Ana de Coro. Venezuela

Karla Paola Campoverde-Molina; Katina Vanessa Bermeo-Pazmiño

Diego Patricio Cisneros-Quintanilla

3. Teletrabajo Offshore: son oficinas cuya ubicación se encuentra en el extranjero, en las cuales las empresas contratan personal en las zonas donde lo requieran.

\section{MÉTODO}

La metodología empleada en la presente investigación es de carácter descriptiva no experimental transversal, ya que se efectuó el estudio de las variables sin manipularlas, para posteriormente realizar el correspondiente análisis, síntesis y conclusión. Se empleó un muestreo por conveniencia, de fácil acceso y disponibilidad de las personas que formaron parte de la investigación, que para este estudio fueron 29 personas del departamento de Secretaría de las Unidades Académicas de la Universidad Católica de Cuenca, a quienes se les aplicó una encuesta y cuestionario en escala Likert de varias alternativas de respuestas, siendo validado por juicio de experto y cálculo de fiabilidad Alfa de Cronbach con resultado de 0,89 siendo catalogado confiable para ser aplicado, así mismo, los datos obtenidos fueron procesados en razón de la estadística descriptiva.

\section{RESULTADOS}

En los resultados obtenidos en las encuestas realizadas al personal de las secretarias de las Unidades Académicas, podemos observar en la figura 1, respecto a si se realizó un análisis del contexto interno y externo de la organización previo a iniciar labores en el teletrabajo, el 51,72\% estuvo de acuerdo de que si se realizó el análisis respectivo siento este el más significativo, un 17,24\% reflejo que está totalmente de acuerdo, un 13,79\% no están ni de acuerdo ni en desacuerdo, un 13,79\% están en desacuerdo y un 3,44\% muy en desacuerdo que no se realizó el análisis adecuado previo a iniciar labores en la modalidad de Teletrabajo. 
CIENCIAMATRIA

Revista Interdisciplinaria de Humanidades, Educación, Ciencia y Tecnología

Año VII. Vol. VII. N¹2. Enero - Junio. 2021

Hecho el depósito de ley: pp201602FA4721

ISSN-L: 2542-3029; ISSN: 2610-802X

Universidad Nacional Experimental Francisco de Miranda (UNEFM). Santa Ana de Coro. Venezuela

Karla Paola Campoverde-Molina; Katina Vanessa Bermeo-Pazmiño

Diego Patricio Cisneros-Quintanilla

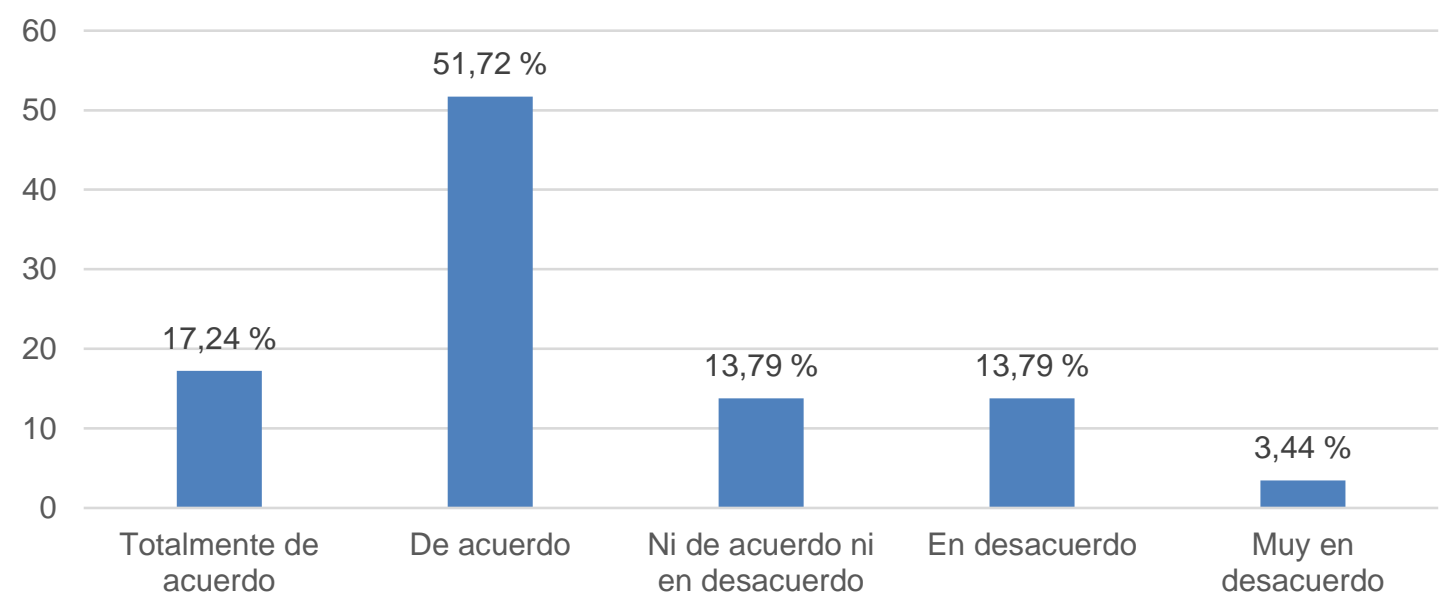

Figura 1. Análisis contexto interno - externo.

A continuación, en la figura 2, respecto a si el personal dispone de recursos tecnológicos para laboral bajo la modalidad de teletrabajo, el 34,48\% estuvo totalmente de acuerdo de que si disponen del equipo tecnológico necesario para poder laborar siento este el más significativo, un $27,58 \%$ reflejo que está de acuerdo, un $10,34 \%$ no están ni de acuerdo ni en desacuerdo, un $24,13 \%$ están en desacuerdo y un 3,44\% están muy en desacuerdo de que no disponen de equipo tecnológico para poder trabajar bajo esta modalidad.

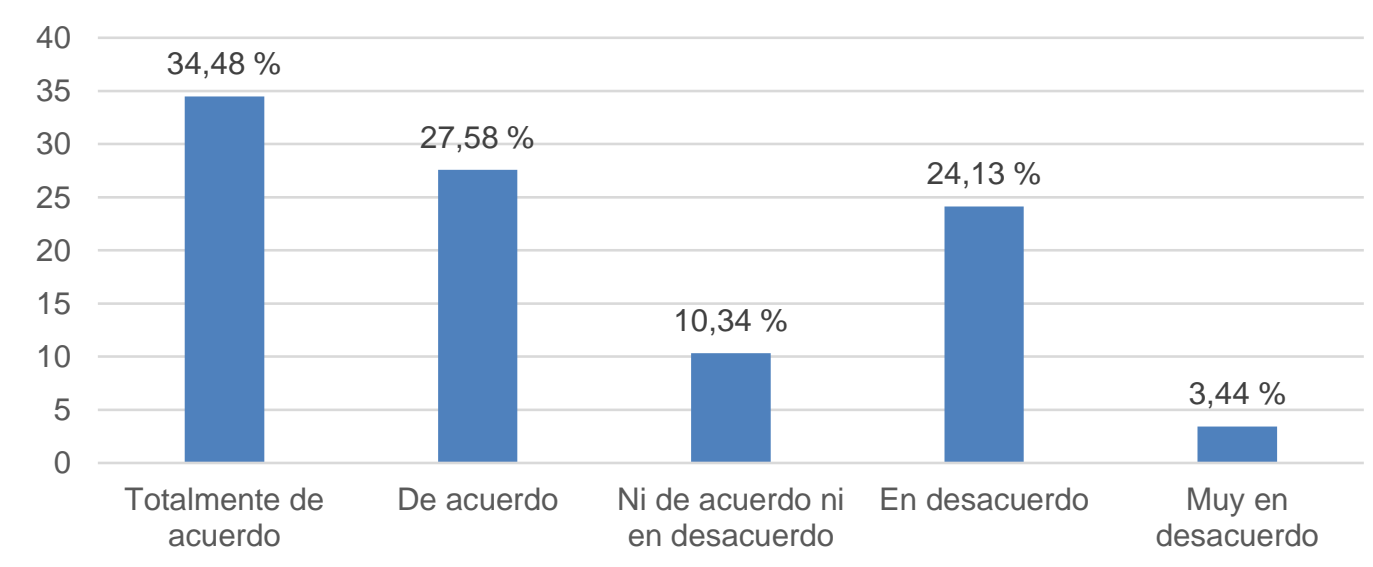

Figura 2. Disponibilidad de recursos tecnológicos. 


\section{CIENCIAMATRIA}

Revista Interdisciplinaria de Humanidades, Educación, Ciencia y Tecnología

Año VII. Vol. VII. N¹2. Enero - Junio. 2021

Hecho el depósito de ley: pp201602FA4721

ISSN-L: 2542-3029; ISSN: 2610-802X

Universidad Nacional Experimental Francisco de Miranda (UNEFM). Santa Ana de Coro. Venezuela

Karla Paola Campoverde-Molina; Katina Vanessa Bermeo-Pazmiño

Diego Patricio Cisneros-Quintanilla

En lo que respecta al aumento en la cantidad de trámites y el tiempo invertido en su desarrollo bajo esta modalidad, como se muestra en la figura 3, el 62,06\% estuvo totalmente de acuerdo en que, si hubo un aumento significativo en el tiempo que le dedican, así como la cantidad de trámites que se gestionan, siendo esta la más significativa, un $34,48 \%$ estuvo de acuerdo y un $3,44 \%$ muy en desacuerdo con respecto a este aspecto.

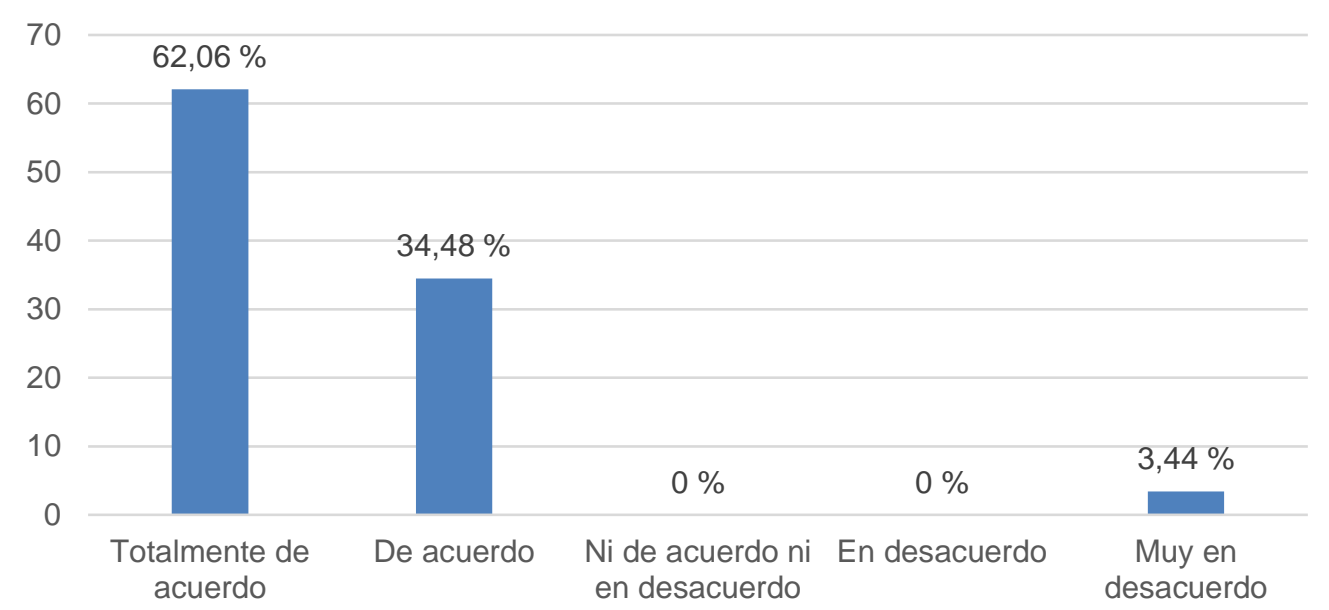

Figura 3. Tiempo y cantidad de trámites.

En cambio, en la figura 4 se observa que, en las actividades desarrolladas bajo Teletrabajo, se obtuvo que el 37,93 \% invierte más tiempo en la actividad de recepción, trámite y respuesta de solicitudes estudiantiles, siendo esta la más significativa, el 24,13\% invierte más tiempo en la elaboración de informes de graduación, el $20,68 \%$ en la elaboración de certificados varios y el 17,24\% en la elaboración de carpetas para enviar a fiscalizar. 
CIENCIAMATRIA

Revista Interdisciplinaria de Humanidades, Educación, Ciencia y Tecnología

Año VII. Vol. VII. N¹2. Enero - Junio. 2021

Hecho el depósito de ley: pp201602FA4721

ISSN-L: 2542-3029; ISSN: 2610-802X

Universidad Nacional Experimental Francisco de Miranda (UNEFM). Santa Ana de Coro. Venezuela

Karla Paola Campoverde-Molina; Katina Vanessa Bermeo-Pazmiño

Diego Patricio Cisneros-Quintanilla

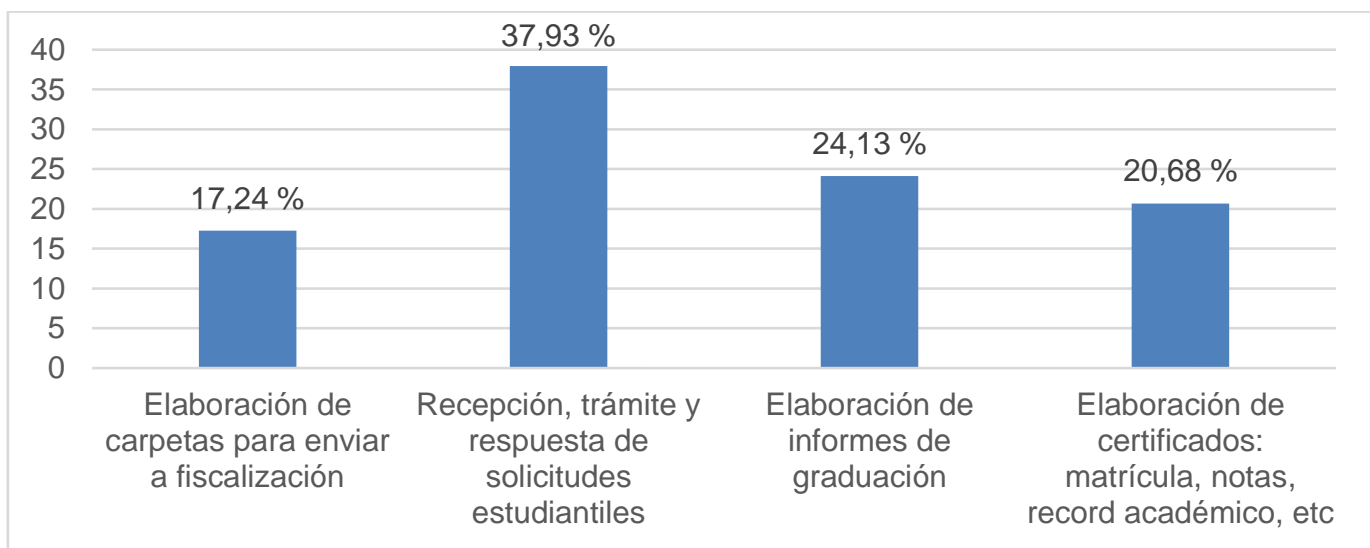

Figura 4: Inversión de tiempo actividades.

Por último, con respecto a si se realiza una evaluación institucional de las actividades realizadas en un periodo determinado, en la figura 5 se observa que, el $44,82 \%$ está de acuerdo con que, si se realiza esta evaluación siendo esta la más significativa, un 17,24\% está totalmente de acuerdo, un 27,58\% no está ni de acuerdo ni en desacuerdo, un 6,89\% está en desacuerdo y un 3, 44\% muy en desacuerdo de que no se realiza una evaluación institucional de las actividades efectuadas.

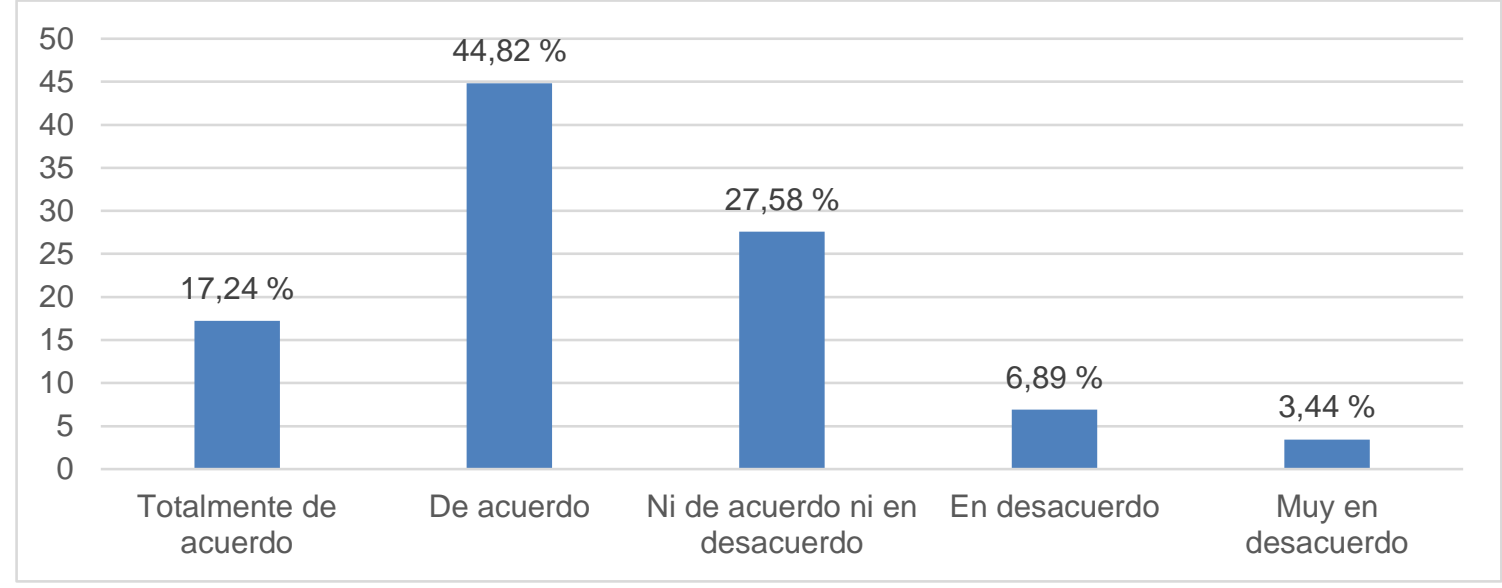

Figura 5: Evaluación institucional. 
CIENCIAMATRIA

Revista Interdisciplinaria de Humanidades, Educación, Ciencia y Tecnología

Año VII. Vol. VII. N¹2. Enero - Junio. 2021

Hecho el depósito de ley: pp201602FA4721

ISSN-L: 2542-3029; ISSN: 2610-802X

Universidad Nacional Experimental Francisco de Miranda (UNEFM). Santa Ana de Coro. Venezuela

Karla Paola Campoverde-Molina; Katina Vanessa Bermeo-Pazmiño

Diego Patricio Cisneros-Quintanilla

\section{PROPUESTA}

La gestión administrativa en la Universidad Católica de Cuenca mediante Teletrabajo durante el confinamiento desarrollada en esta investigación, en su esquema se ha determinado cuatro etapas, las cuales reflejan de forma organizada y detallada cada uno de los procesos que involucra la gestión documental en los departamentos de Secretaría. A continuación, en la figura 6 se presenta el esquema de la propuesta:

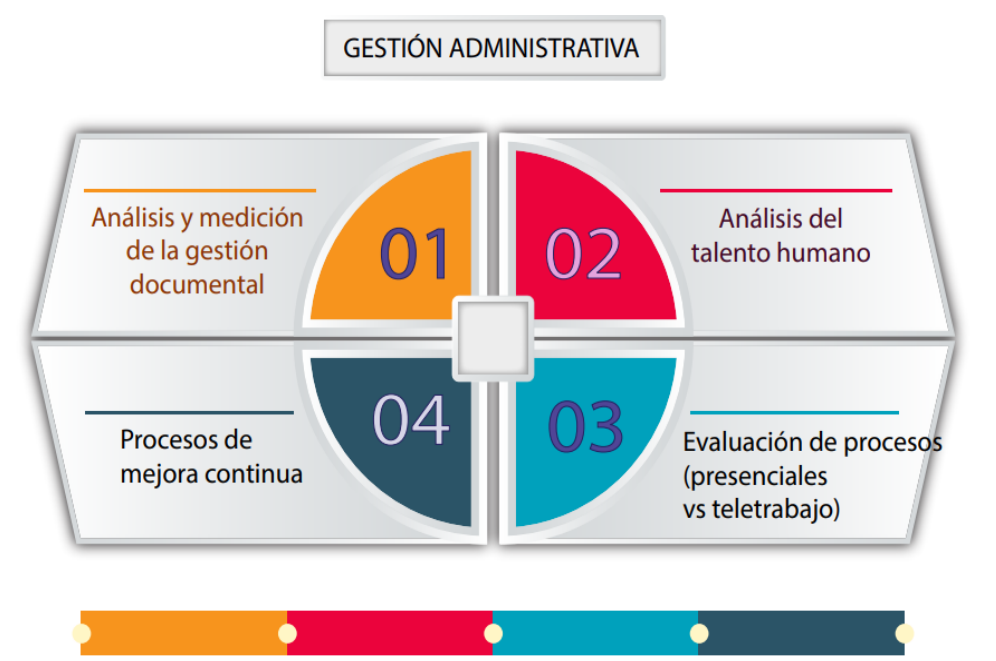

Figura 6. Esquema de la propuesta

\section{Análisis y medición de la gestión documental}

Como primera etapa del desarrollo del esquema de nuestra propuesta, tenemos el análisis y medición de la gestión documental, para esto se realizó un análisis de los procesos en común y más sobresalientes que se desarrollan en las secretarias de las Unidades Académicas, así como su porcentaje de realización en cada periodo académico, tal como se observa en la Tabla 1. 


\section{CIENCIAMATRIA}

Revista Interdisciplinaria de Humanidades, Educación, Ciencia y Tecnología

Año VII. Vol. VII. No12. Enero - Junio. 2021

Hecho el depósito de ley: pp201602FA4721

ISSN-L: 2542-3029; ISSN: 2610-802X

Universidad Nacional Experimental Francisco de Miranda (UNEFM). Santa Ana de Coro. Venezuela

Karla Paola Campoverde-Molina; Katina Vanessa Bermeo-Pazmiño

Diego Patricio Cisneros-Quintanilla

\section{Tabla 1.}

Análisis y medición de la gestión documental.

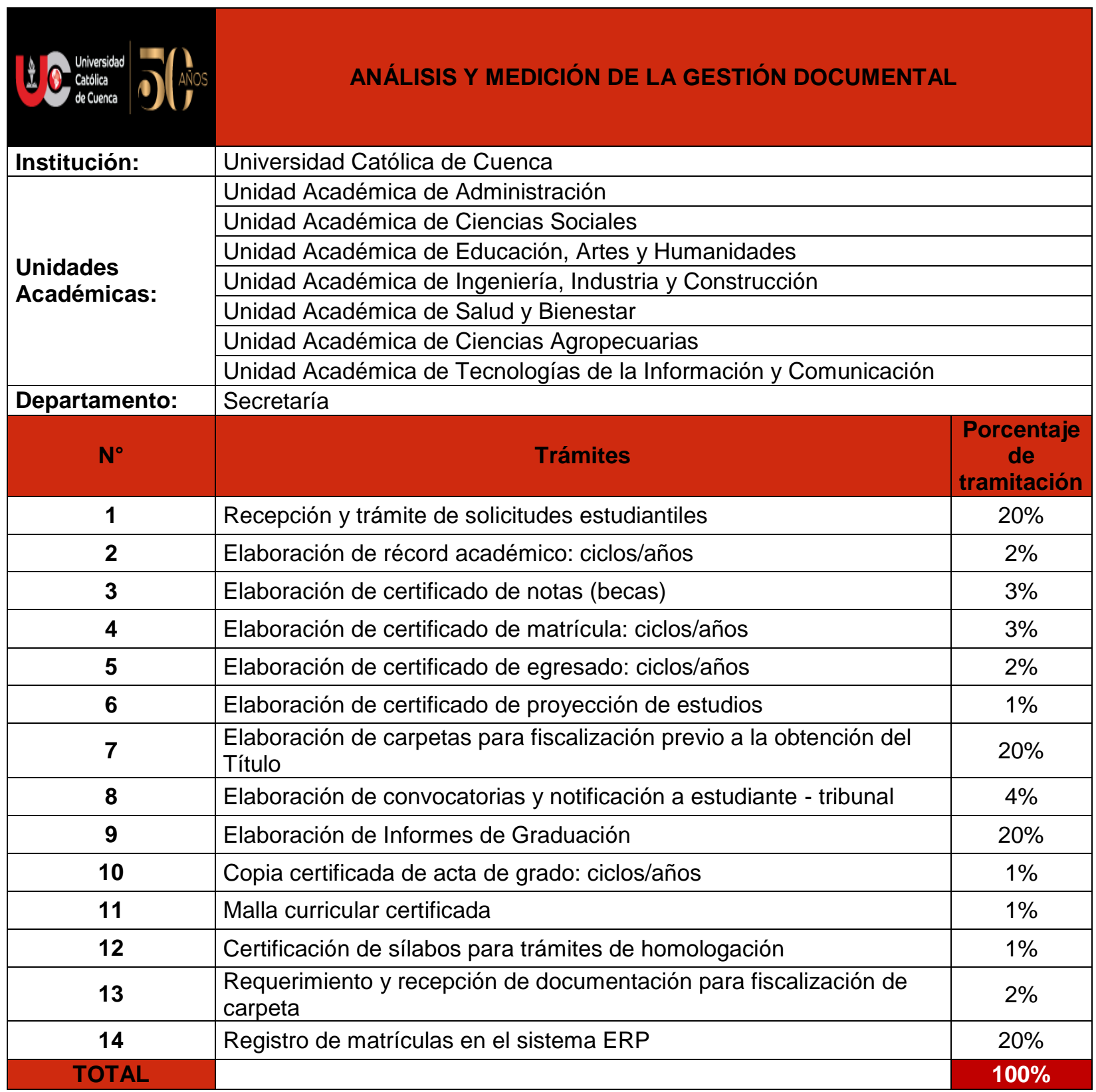

Fuente: Elaboración propia. 


\section{CIENCIAMATRIA}

Revista Interdisciplinaria de Humanidades, Educación, Ciencia y Tecnología

Año VII. Vol. VII. Nº12. Enero - Junio. 2021

Hecho el depósito de ley: pp201602FA4721

ISSN-L: 2542-3029; ISSN: 2610-802X

Universidad Nacional Experimental Francisco de Miranda (UNEFM). Santa Ana de Coro. Venezuela

Karla Paola Campoverde-Molina; Katina Vanessa Bermeo-Pazmiño

Diego Patricio Cisneros-Quintanilla

\section{Análisis del talento humano}

Como se observa en la Tabla 2, se continua con la segunda etapa del desarrollo de la propuesta, en este punto se analiza y detalla el personal, responsables y departamento que participa en la gestión de cada uno de los trámites realizados por las secretarías de las Unidades Académicas.

Tabla 2.

Análisis del Talento Humano.

\begin{tabular}{|c|c|c|c|c|}
\hline 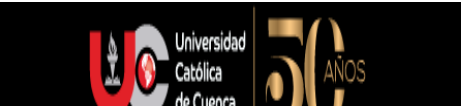 & \multicolumn{4}{|c|}{ ANÁLISIS DEL TALENTO HUMANO } \\
\hline \multirow{2}{*}{$\begin{array}{l}\text { Institución: } \\
\text { Departamento: }\end{array}$} & \multicolumn{4}{|c|}{ Universidad Católica de Cuenca } \\
\hline & \multicolumn{4}{|l|}{ Secretaría } \\
\hline Trámite & Involucrado & $\begin{array}{l}\text { Recepción-Revisión- } \\
\text { Elaboración }\end{array}$ & $\begin{array}{c}\text { Firmas de } \\
\text { Responsabilidad }\end{array}$ & $\begin{array}{l}\text { Departamento } \\
\text { Involucrado }\end{array}$ \\
\hline \multirow{2}{*}{$\begin{array}{l}\text { Recepción y trámite de } \\
\text { solicitudes estudiantiles }\end{array}$} & \multirow{2}{*}{ Estudiante } & \multirow{2}{*}{ Auxiliar - Secretaría } & Secretario & Secretaría \\
\hline & & & Decano & Decanato \\
\hline \multirow{2}{*}{$\begin{array}{l}\text { Elaboración de récord } \\
\text { académico: ciclos/años }\end{array}$} & Estudiante & \multirow{2}{*}{ Auxiliar - Secretaría } & Secretario & Secretaría \\
\hline & Graduado & & Secretario General & Secretaría General \\
\hline $\begin{array}{l}\text { Elaboración de certificado } \\
\text { de notas (becas) }\end{array}$ & Estudiante & Auxiliar - Secretaría & Secretario & Secretaría \\
\hline \multirow{2}{*}{$\begin{array}{l}\text { Elaboración de certificado } \\
\text { de matrícula: ciclos/años }\end{array}$} & \multirow{2}{*}{ Estudiante } & \multirow{2}{*}{ Auxiliar - Secretaría } & Secretario & Secretaría \\
\hline & & & Secretario General & Secretaría General \\
\hline $\begin{array}{l}\text { Elaboración de certificado } \\
\text { de egresado: ciclos/años }\end{array}$ & Estudiante & Auxiliar - Secretaría & Secretario & Secretaría \\
\hline \multirow{2}{*}{$\begin{array}{l}\text { Elaboración de certificado } \\
\text { de proyección de estudios }\end{array}$} & \multirow{2}{*}{ Estudiante } & \multirow{2}{*}{ Auxiliar - Secretaría } & Secretario & Secretaría \\
\hline & & & Secretario General & Secretaría General \\
\hline \multirow{2}{*}{$\begin{array}{l}\text { Elaboración de carpetas } \\
\text { para fiscalización previo a la } \\
\text { obtención del Título }\end{array}$} & \multirow[b]{2}{*}{ Estudiante } & \multirow[b]{2}{*}{ Auxiliar - Secretaría } & Secretario & Secretaría \\
\hline & & & $\begin{array}{c}\text { Secretario General } \\
\text { Fiscalización }\end{array}$ & $\frac{\text { Secretaría General }}{\text { Fiscalización }}$ \\
\hline $\begin{array}{l}\text { Elaboración de } \\
\text { convocatorias y notificación } \\
\text { a estudiante - tribunal }\end{array}$ & Estudiante & Auxiliar - Secretaría & Secretario & Secretaría \\
\hline \multirow{2}{*}{$\begin{array}{l}\text { Elaboración de Informes de } \\
\text { Graduación }\end{array}$} & \multirow{2}{*}{ Estudiante } & \multirow{2}{*}{ Auxiliar - Secretaría } & Secretario & Secretaría \\
\hline & & & Secretario General & Secretaría General \\
\hline \multirow{2}{*}{$\begin{array}{l}\text { Copia certificada de acta de } \\
\text { grado: ciclos/años }\end{array}$} & \multirow{2}{*}{ Graduado } & \multirow{2}{*}{ Auxiliar - Secretaría } & Secretario & Secretaría \\
\hline & & & Secretario General & Secretaría General \\
\hline \multirow{3}{*}{ Malla curricular certificada } & \multirow[t]{2}{*}{ Estudiante } & \multirow{2}{*}{ Auxiliar - Secretaría } & Secretario & Secretaría \\
\hline & & & Secretario General & Secretaría General \\
\hline & Estudiante & Auxiliar - Secretaría & Secretario & Secretaría \\
\hline
\end{tabular}




\section{CIENCIAMATRIA}

Revista Interdisciplinaria de Humanidades, Educación, Ciencia y Tecnología

Año VII. Vol. VII. Nº12. Enero - Junio. 2021

Hecho el depósito de ley: pp201602FA4721

ISSN-L: 2542-3029; ISSN: 2610-802X

Universidad Nacional Experimental Francisco de Miranda (UNEFM). Santa Ana de Coro. Venezuela

Karla Paola Campoverde-Molina; Katina Vanessa Bermeo-Pazmiño

Diego Patricio Cisneros-Quintanilla

\begin{tabular}{|c|c|c|c|c|}
\hline $\begin{array}{l}\text { Certificación de sílabos para } \\
\text { trámites de homologación }\end{array}$ & & & Secretario General & Secretaría General \\
\hline $\begin{array}{l}\text { Requerimiento y recepción } \\
\text { de documentación para } \\
\text { fiscalización de carpeta }\end{array}$ & Estudiante & Auxiliar - Secretaría & Secretario & Secretaría \\
\hline \multirow{2}{*}{$\begin{array}{l}\text { Registro de matrículas en el } \\
\text { sistema ERP }\end{array}$} & \multirow{2}{*}{ Estudiante } & \multirow{2}{*}{ Auxiliar - Secretaría } & Secretario & Secretaría \\
\hline & & & Secretario General & Secretaría General \\
\hline
\end{tabular}

Fuente: Elaboración propia.

\section{Evaluación de procesos (presenciales vs teletrabajo)}

Una vez finalizado el análisis del talento humano que interviene en los diferentes procesos, se continua con la tercera etapa del desarrollo de la propuesta, en la Tabla 3 se analiza y detalla paso a paso los procesos realizados de forma presencial y bajo la modalidad de Teletrabajo por el departamento de Secretaría.

\section{Tabla 3.}

Evaluación de procesos (presenciales vs teletrabajo)

\begin{tabular}{|c|c|c|c|c|c|}
\hline 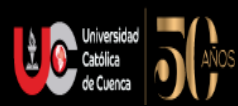 & \multicolumn{5}{|c|}{ EVALUACIÓN DE PROCESOS (PRESENCIALES VS TELETRABAJO) } \\
\hline Institución: & \multicolumn{5}{|c|}{ Universidad Católica de Cuenca } \\
\hline Departamento: & \multicolumn{5}{|c|}{ Secretaría } \\
\hline \multicolumn{3}{|r|}{ PRESENCIAL } & \multicolumn{3}{|r|}{ TELETRABAJO } \\
\hline TRÁMITE & & PROCESO & TRÁMITE & & PROCESO \\
\hline \multirow{5}{*}{$\begin{array}{l}\text { Recepción y } \\
\text { trámite de } \\
\text { solicitudes } \\
\text { estudiantiles }\end{array}$} & \multirow[t]{2}{*}{1} & \multirow[t]{2}{*}{ Ingreso y revisión de solicitud física } & \multirow{5}{*}{$\begin{array}{l}\text { Recepción y } \\
\text { trámite de } \\
\text { solicitudes } \\
\text { estudiantiles }\end{array}$} & 1 & $\begin{array}{l}\text { Recepción, revisión y clasificación de } \\
\text { correos recibidos de recepción } \\
\text { documental }\end{array}$ \\
\hline & & & & 2 & $\begin{array}{l}\text { Envío de correos electrónicos al } \\
\text { secretario }\end{array}$ \\
\hline & \multirow[b]{3}{*}{3} & \multirow[t]{2}{*}{ Resolución Decano } & & 3 & $\begin{array}{l}\text { Envío de correos electrónicos para } \\
\text { resolución - Decano }\end{array}$ \\
\hline & & & & 4 & Recepción de correos con la resolución \\
\hline & & Entrega de solicitud al estudiante & & 5 & $\begin{array}{l}\text { Envió de respuesta a estudiante/docente } \\
\text { del trámite de solicitud vía correo } \\
\text { electrónico }\end{array}$ \\
\hline & & & & & \\
\hline \multirow{2}{*}{$\begin{array}{l}\text { Elaboración de } \\
\text { carpetas - } \\
\text { fiscalización }\end{array}$} & 1 & $\begin{array}{l}\text { Requerimiento de carpeta de } \\
\text { titulación mediante oficio a colecturía }\end{array}$ & \multirow{2}{*}{$\begin{array}{l}\text { Elaboración } \\
\text { de carpetas - } \\
\text { fiscalización }\end{array}$} & 1 & $\begin{array}{l}\text { Requerimiento vía correo electrónico de } \\
\text { certificados de no adeudar y prorrogas a } \\
\text { colecturía para carpeta de titulación } \\
\end{array}$ \\
\hline & 2 & Recepción trabajo de titulación físico & & 2 & Recepción trabajo de titulación digital \\
\hline
\end{tabular}




\section{CIENCIAMATRIA}

Revista Interdisciplinaria de Humanidades, Educación, Ciencia y Tecnología

Año VII. Vol. VII. №12. Enero - Junio. 2021

Hecho el depósito de ley: pp201602FA4721

ISSN-L: 2542-3029; ISSN: 2610-802X

Universidad Nacional Experimental Francisco de Miranda (UNEFM). Santa Ana de Coro. Venezuela

Karla Paola Campoverde-Molina; Katina Vanessa Bermeo-Pazmiño

Diego Patricio Cisneros-Quintanilla

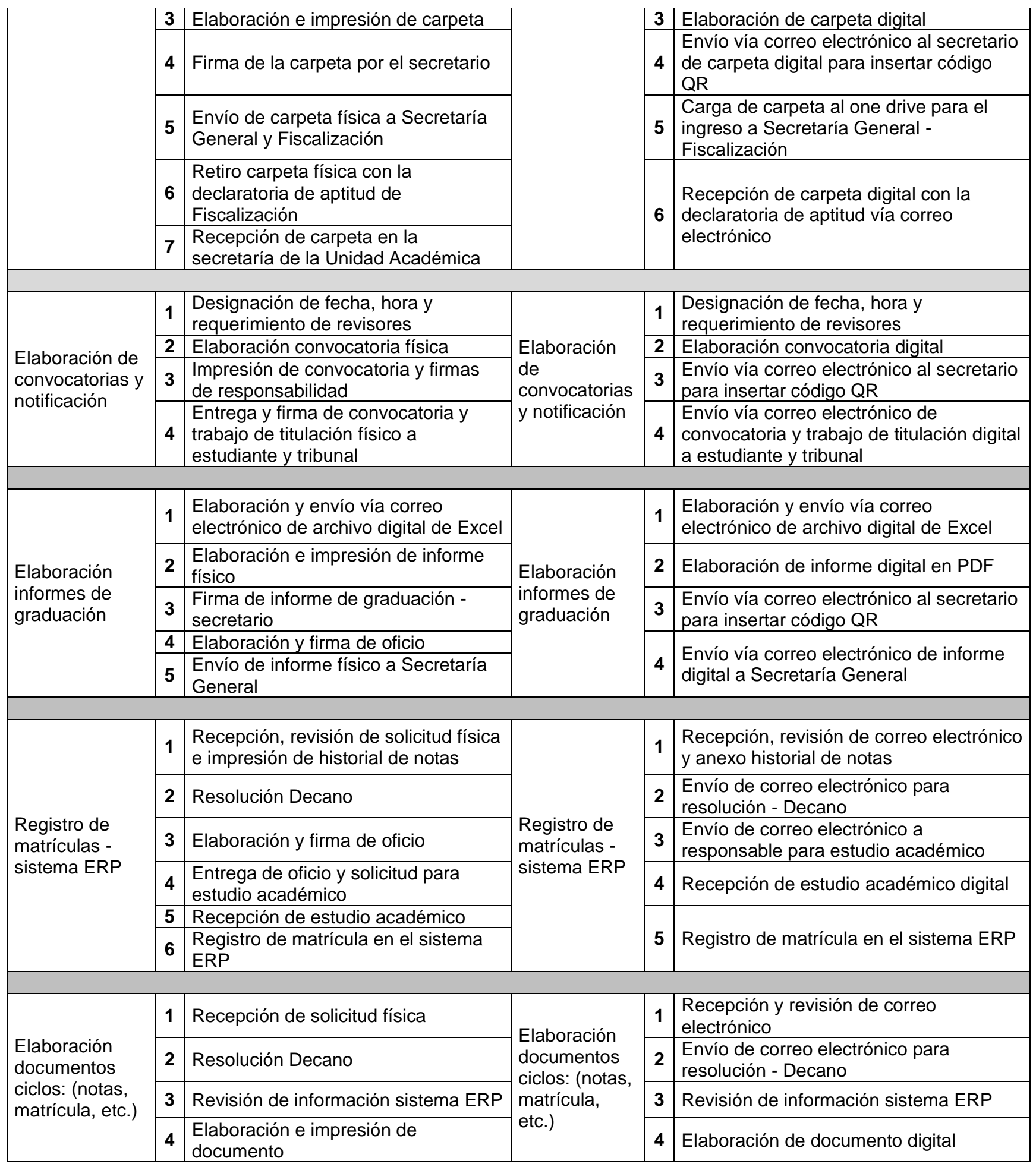




\section{CIENCIAMATRIA}

Revista Interdisciplinaria de Humanidades, Educación, Ciencia y Tecnología

Año VII. Vol. VII. Nº12. Enero - Junio. 2021

Hecho el depósito de ley: pp201602FA4721

ISSN-L: 2542-3029; ISSN: 2610-802X

Universidad Nacional Experimental Francisco de Miranda (UNEFM). Santa Ana de Coro. Venezuela

Karla Paola Campoverde-Molina; Katina Vanessa Bermeo-Pazmiño

Diego Patricio Cisneros-Quintanilla

\begin{tabular}{|c|c|c|c|c|c|}
\hline & 5 & $\begin{array}{l}\text { Envío para certificación - firmas } \\
\text { responsabilidad }\end{array}$ & & 5 & $\begin{array}{l}\text { Envío vía correo electrónico certificación: } \\
\text { código QR }\end{array}$ \\
\hline & 6 & Recepción de documento certificado & & \multirow[b]{2}{*}{6} & \multirow{2}{*}{$\begin{array}{l}\text { Envío vía correo electrónico de } \\
\text { documento al estudiante }\end{array}$} \\
\hline & 7 & $\begin{array}{l}\text { Entrega de documento físico al } \\
\text { estudiante }\end{array}$ & & & \\
\hline & & & & & \\
\hline \multirow{7}{*}{$\begin{array}{l}\text { Elaboración } \\
\text { documentos } \\
\text { años: (notas, } \\
\text { matrícula, etc.) }\end{array}$} & 1 & Recepción de solicitud física & \multirow{7}{*}{$\begin{array}{l}\text { Elaboración } \\
\text { documentos } \\
\text { años: (notas, } \\
\text { matrícula, } \\
\text { etc.) }\end{array}$} & 1 & $\begin{array}{l}\text { Recepción y revisión de correo } \\
\text { electrónico }\end{array}$ \\
\hline & 2 & Resolución Decano & & 2 & $\begin{array}{l}\text { Envío de correo electrónico para } \\
\text { resolución - Decano }\end{array}$ \\
\hline & 3 & $\begin{array}{l}\text { Revisión de información en archivo } \\
\text { físico (años) }\end{array}$ & & 3 & $\begin{array}{l}\text { Ir a revisar el archivo físico a traer la } \\
\text { documentación requerida }\end{array}$ \\
\hline & 4 & $\begin{array}{l}\text { Elaboración e impresión de } \\
\text { documento }\end{array}$ & & 4 & Elaboración de documento digital \\
\hline & 5 & $\begin{array}{l}\text { Envío para certificación - firmas } \\
\text { responsabilidad }\end{array}$ & & 5 & $\begin{array}{l}\text { Envío vía correo electrónico para } \\
\text { certificación: código QR }\end{array}$ \\
\hline & 6 & Recepción de documento certificado & & \multirow{2}{*}{6} & \multirow{2}{*}{$\begin{array}{l}\text { Envío vía correo electrónico del } \\
\text { documento al estudiante }\end{array}$} \\
\hline & 7 & $\begin{array}{l}\text { Entrega de documento físico al } \\
\text { estudiante }\end{array}$ & & & \\
\hline & & & & & \\
\hline \multirow{2}{*}{$\begin{array}{l}\text { Requerimiento - } \\
\text { recepción doc. } \\
\text { carpeta }\end{array}$} & 1 & $\begin{array}{l}\text { Entrega de listado de requisitos al } \\
\text { estudiante }\end{array}$ & \multirow{2}{*}{$\begin{array}{l}\text { Requerimient } \\
o \text { - recepción } \\
\text { doc. carpeta }\end{array}$} & 1 & $\begin{array}{l}\text { Envío vía correo electrónico de requisitos } \\
\text { para fiscalización de carpeta al } \\
\text { estudiante }\end{array}$ \\
\hline & 2 & $\begin{array}{l}\text { Recepción y revisión de la } \\
\text { documentación física }\end{array}$ & & 2 & $\begin{array}{l}\text { Recepción y revisión de la } \\
\text { documentación digital vía correo } \\
\text { electrónico }\end{array}$ \\
\hline
\end{tabular}

Fuente: Elaboración propia.

\section{Procesos de mejora continua}

Una vez finalizada la evaluación de procesos realizados presencialmente vs teletrabajo, se continua con la cuarta y última etapa del desarrollo de la propuesta, si bien hemos podido observar que hay una diferenciación en la gestión de los procesos realizados bajo estas dos modalidades, generándose una disminución en los pasos de los procesos realizados bajo Teletrabajo lo cual refleja el correcto funcionamiento y eficiencia de los mismos, sin embargo se determinó un proceso en el cual se puede realizar una mejora significativa que nos permita reducir el tiempo invertido para su gestión, este es la elaboración de documentos pertenecientes a la modalidad de años, ya que para su elaboración se debe recurrir a los archivos físicos que reposan en las Unidades Académicas. 
CIENCIAMATRIA

Revista Interdisciplinaria de Humanidades, Educación, Ciencia y Tecnología

Año VII. Vol. VII. N¹2. Enero - Junio. 2021

Hecho el depósito de ley: pp201602FA4721

ISSN-L: 2542-3029; ISSN: 2610-802X

Universidad Nacional Experimental Francisco de Miranda (UNEFM). Santa Ana de Coro. Venezuela

Karla Paola Campoverde-Molina; Katina Vanessa Bermeo-Pazmiño

Diego Patricio Cisneros-Quintanilla

Para lograr esto, se propone realizar un plan para la digitalización de los archivos físicos, tal como se observa en la Tabla 4, para tener acceso de forma rápida a los archivos, así como un control y respaldo de la documentación física existente, sin tener que ir a la Unidad Académica para la obtención de información.

Tabla 4.

Procesos de mejora continua.

\begin{tabular}{|c|c|c|}
\hline 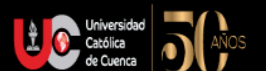 & \multicolumn{2}{|l|}{ PROCESOS DE MEJORA CONTINUA } \\
\hline Institución: & \multirow{2}{*}{\multicolumn{2}{|c|}{\begin{tabular}{|l|} 
Universidad Católica de Cuenca \\
Unidad Académica de Administración
\end{tabular}}} \\
\hline & & \\
\hline & \multicolumn{2}{|l|}{ Unidad Académica de Ciencias Sociales } \\
\hline & \multicolumn{2}{|l|}{ Unidad Académica de Educación, Artes y Humanidades } \\
\hline $\begin{array}{l}\text { Unidades } \\
\text { Académicas. }\end{array}$ & \multicolumn{2}{|l|}{ Unidad Académica de Ingeniería, Industria y Construcción } \\
\hline & \multicolumn{2}{|l|}{ Unidad Académica de Salud y Bienestar } \\
\hline & \multicolumn{2}{|l|}{ Unidad Académica de Ciencias Agropecuarias } \\
\hline & \multicolumn{2}{|l|}{ Unidad Académica de Tecnologías de la Información y Comunicación } \\
\hline Departamento: & \multicolumn{2}{|l|}{ Secretaría } \\
\hline $\mathbf{N}^{\circ}$ & Proceso de digitalización & Involucrados \\
\hline \multirow{2}{*}{1} & \multirow{2}{*}{ Revisión de los archivos físicos a digitalizar } & Auxiliar - Secretaría \\
\hline & & Secretario \\
\hline \multirow{2}{*}{2} & \multirow{2}{*}{ Separación de archivos físicos por carreras } & Auxiliar - Secretaría \\
\hline & & Secretario \\
\hline \multirow{2}{*}{3} & \multirow{2}{*}{ Designación de responsables para digitalización de archivos por carrera } & Auxiliar - Secretaría \\
\hline & & Secretario \\
\hline \multirow{2}{*}{4} & \multirow{2}{*}{ Establecimiento de tiempos y metas a alcanzar } & Auxiliar - Secretaría \\
\hline & & Secretario \\
\hline \multirow[t]{2}{*}{5} & \multirow{2}{*}{$\begin{array}{l}\text { Digitalización de archivos físicos en formato PDF (lectura) que permita } \\
\text { búsqueda }\end{array}$} & Auxiliar - Secretaría \\
\hline & & Secretario \\
\hline \multirow{2}{*}{6} & \multirow{2}{*}{$\begin{array}{l}\text { Creación de carpetas por carrera para almacenamiento de archivos } \\
\text { digitalizados (base de datos) }\end{array}$} & Auxiliar - Secretaría \\
\hline & & Secretario \\
\hline
\end{tabular}

Fuente: Elaboración propia. 


\section{CONCLUSIONES}

La pandemia del COVID - 19, obligo a la mayoría de las organizaciones entre estas las Instituciones de Educación Superior, a cambiar la gestión administrativa de sus procesos y adaptarlas rápidamente en el marco del Teletrabajo, para poder así retomar el desarrollo de sus actividades diarias.

La Universidad Católica de Cuenca, fue parte del cambio debido a la emergencia sanitaria, sin embargo, realizó una correcta capacitación a sus distintos departamentos para poder iniciar el desarrollo de sus actividades que se encontraban paralizadas bajo la modalidad de Teletrabajo, siendo esta una herramienta de innovación que permitió no exponer y cuidar la salud de sus trabajadores.

Se determinó que el personal cuenta con el equipo tecnológico adecuado para laborar bajo esta modalidad y que existe un buen nivel de funcionamiento y adaptación en los trámites desarrollados mediante Teletrabajo en las secretarías de las Unidades Académicas, sin embargo, se estableció un plan de digitalización en los archivos físicos que permitirá tener un control sobre la información y una disminución en el tiempo que conlleva la tramitación de estos documentos.

\section{REFERENCIAS CONSULTADAS}

Ansoff, I. (1965). Corporate Strategy. Estados Unidos: M cGraw. Hill.

Belzunegui , E. (2001). Diversificación de las condiciones de trabajo y cambios organizativos en las empresas: un estudio sobre el teletra-bajo [Diversification of working conditions and organizational changes in companies: a study on teletraining]. Barcelona.

Brooking, A. (1997). El capital intelectual: el principal activo de las empresas del tercer milenio [Intellectual capital: the main asset of companies in the third millennium]. Buenos Aires: Ediciones Paidos.

Buira, J. (2012). El Teletrabajo. Entre el mito y la realidad [Teleworking. Between the myth and reality]. Barcelona: UOC. Obtenido de https://n9.cl/0gw4 
Cano, R., Castro, R., \& Peñafiel, E. (2017). Ventajas y desventajas del teletrabajo aplicados en la ciudad de Lima- Perú, 2016 [Advantages and disadvantages of teleworking applied in the city of Lima - Peru, 2016]. 55-56. http://repositorio.ulasamericas.edu.pe/handle/upa/156

Cruz-Mundet, J. (2006). La gestión de documentos en las organizaciones [Document management in organizations]. Madrid: Ediciones Pirámide.

Cuervo, A. (1999). El gobierno de la empresa [Governance of the company]. Anuario de la facultad de Derecho de la Universidad Autónoma de Madrid, 95-108.

Draf, R. (2006). La experiencia del liderazgo [The leadership experience]. México: Cengage.

Duran, S., Crissien, J., Virviescas, J., \& García, J. (2017). Estrategias gerenciales para la formación de equipos de trabajo en empresas constructoras del Caribe Colombiano [Management strategies for the formation of work teams in construction companies in the Colombian Caribbean]. Revista Espacios, 38(13), 26-28.

Escalante, Z, \& Ugas, L. (2005). El teletrabajo y sus implicaciones legales en el estado Zulia. Télématique, 4(1),1-28.

Fayol, H. (1980). Administración Industrial y General [Industrial and General Administration]. Buenos Aires: El Ateneo.

García, J. (2013). Pensamiento estratégico y planificación estratégica: desafío futuro hacia la responsabilidad social organizacional [Strategic thinking and strategic planning: future challenge towards organizational social responsibility]. Venezuela: Astrodata.

Havriluk, L., \& Delgado, Y. (2010). Mujer, cyberfeminismo y teletrabajo [Women, cyberfeminism and telework]. Compendium, 13(24),61-78

Koontz, H., \& Weihrich, H. (1998). Administración una perspectiva global [Management a global perspective]. México: McGraw Hill.

Louffat, E. (2015). Administración: fundamentos del proceso administrativo [Administration: fundamentals of the administrative process]. Buenos Aires: Cengage Learning . 
Revista Interdisciplinaria de Humanidades, Educación, Ciencia y Tecnología

Año VII. Vol. VII. N¹2. Enero - Junio. 2021

Hecho el depósito de ley: pp201602FA4721

ISSN-L: 2542-3029; ISSN: 2610-802X

Universidad Nacional Experimental Francisco de Miranda (UNEFM). Santa Ana de Coro. Venezuela

Karla Paola Campoverde-Molina; Katina Vanessa Bermeo-Pazmiño

Diego Patricio Cisneros-Quintanilla

Martin, P. (2018). Teletrabajo y comercio electronico [Teleworking and e-commerce]. España: Ministerio de Educación. Obtenido de https://n9.cl/1aw2s

Moody, P. (1983). Decision making: methods for better decisions. New York: Mc. GrawHill.

Münch, L., \& García , J. (2004). Fundamentos de administración. México: Trillas.

Nilles, J. (1976). The Telecommunications-Transportation Tradeoff. Options for Tomorrow. NewYork: John Wiley \& Sons.

Osio, L. (2010). El Teletrabajo: Una opción en la era digital [Teleworking: An option in the digital age]. Observatorio Laboral Revista Venezolana, 3(5), 93-109.

Pantoja-Aguilar, M., \& Garza-Treviño, J. (2019). Etapas de la administración: hacia un enfoque sistémico. Revista EAN, 139154. https://dx.doi.org/10.21158/01208160.n87.2019.2412

Perez-Carballo, J. (2008). Control de la gestión empresarial. Madrid: ESIK.

Porter, M. (1980). Estrategia competitiva [Competitive strategy]. Buenos Aires: Javier Vergara.

Robbins, S. (1987). Administración teórica y práctica [Theoretical and practical administration]. México: Prentice-Hall Hispanoamerica S.A.

Rodríguez, D., Erazo, J., \& Narváez, C. (2019). Técnicas cuantitativas de investigación de mercados aplicadas al consumo de carne en la generación millennial de la ciudad de Cuenca (Ecuador). Revista Espacios, 40(32), 20.

Romero, J. (2006). La relación de trabajo y sus variantes [The working relationship and its variations]. Letras jurídicas, 13, 247-260.

Russo, P. (2009). Gestión documental en las organizaciones [Documentary management in organizations]. Barcelona: UOC. Obtenido de https://n9.cl/bsg4

Sánchez, A. (2014). La gestión de documentos como estrategia de innovación empresarial [Document management as a business innovation strategy]. Revista Venezolana de Información, Tecnología y Conocimiento, 25-50. Obtenido de https://n9.cl/jmles 


\section{CIENCIAMATRIA}

Revista Interdisciplinaria de Humanidades, Educación, Ciencia y Tecnología

Año VII. Vol. VII. N¹2. Enero - Junio. 2021

Hecho el depósito de ley: pp201602FA4721

ISSN-L: 2542-3029; ISSN: 2610-802X

Universidad Nacional Experimental Francisco de Miranda (UNEFM). Santa Ana de Coro. Venezuela

Karla Paola Campoverde-Molina; Katina Vanessa Bermeo-Pazmiño

Diego Patricio Cisneros-Quintanilla

Tünnermann-Bernheim, C. (2007). La Universidad necesaria para el siglo XXI. Editorial HISPAMER, Managua.

(C2021 por los autores. Este artículo es de acceso abierto y distribuido según los términos y condiciones de la licencia Creative Commons Atribución-NoComercial-Compartirlgual 4.0 Internacional (CC BY-NC-SA 4.0)

(https://creativecommons.org/licenses/by-nc-sa/4.0/). 